\title{
Husserl, Heidegger y el problema de la reflexión ${ }^{1}$
}

\section{Husserl, Heidegger, and the Problem of Reflection}

\author{
Jesús Adrián ESCUDERO \\ (Universidad Autónoma de Barcelona)
}

Recibido: 08/01/2013

Aceptado: 19/03/2013

\section{Resumen}

La idea de que la fenomenología de Husserl representa una suerte de filosofía reflexiva, basada en una metodología que desarrolla la tradición cartesiana, se ha convertido en una creencia ampliamente difundida en la literatura filosófica. Este énfasis puesto por Husserl en la reflexión fue arduamente criticado por Heidegger. Desde entonces resulta frecuente encontrarse con la afirmación de que Husserl y Heidegger desarrollan dos conceptos de fenomenología diferentes, incluso antagónicos. No se trata de seguir alimentando esta discusión historiográfica. Aquí, por una parte, se muestra el complejo proceso de desarrollo de la fenomenología hermenéutica de Heidegger en el transcurso de sus primeras lecciones de Friburgo (1919-1923) y Marburgo (1924-1928) y, por otra, se sopesan algunas de las observaciones críticas de Heidegger a Husserl a la luz de evidencias textuales de la fenomenología husserliana, ignoradas no sólo por Heidegger, sino también por un sorprendente número de reconocidos especialistas en el campo de la filosofía, de las ciencias cognitivas y de la filosofía de la mente.

Palabras clave: constitución, fenomenología genética, hermenéutica y reflexiva, síntesis pasiva y activa.

\footnotetext{
1 El presente trabajo se enmarca en el proyecto de investigación FFI 2009-13187 financiado por el Ministerio de Ciencia e Innovación y en la Beca para Investigadores Avanzados de la Fundación Humboldt.
} 


\begin{abstract}
The idea that Husserl's phenomenology is a kind of reflective philosophy inspired by the Cartesian tradition has become a commonplace in the philosophical literature. Heidegger was one of the first thinkers who criticized the Husserlian emphasis on reflection. Since then it is easy to find the affirmation that Husserl and Heidegger developed two different, even antagonistic concepts of phenomenology. Here is not the place to continue embracing this discussion. One the one hand, the present article shows the complex development process of Heidegger's hermeneutic phenomenology in the course of his first lectures in Freiburg (1919-1923) and Marburg (1924-1928). On the other hand, it weighs up some of Heidegger's critical remarks regarding the reflective nature of Husserlian phenomenology in the light of important textual evidences ignored not only by Heidegger, but also by a surprising number of specialists in the fields of philosophy, cognitive sciences, and philosophy of mind.
\end{abstract}

Keywords: constitution, genetic, hermeneutic and reflective phenomenology, passive and active synthesis.

La idea de que la fenomenología de Husserl representa una suerte de filosofía reflexiva, basada en una metodología introspectiva que desarrolla la tradición cartesiana, se ha convertido en una creencia ampliamente difundida. Tanto en la filosofía analítica como en la continental encontramos a muchos pensadores que rechazan la primacía de la reflexión y la metodología solipsista supuestamente defendida por Husserl. 2 Pero cualquier persona que esté familiarizada con la fenomenolo-

\footnotetext{
2 Por citar algunos ejemplos bien conocidos, en el contexto de la filosofía continental encontramos este tipo de crítica en los trabajos de Natorp, Heidegger, Sartre, Habermas y Herrmann (véanse, respectivamente, Natorp, P. "Husserls Ideen einer reinen Phänomenologie", Logos, 7, 1917/18, pp. 215-240; Heidegger, M.: Die Idee der Philosophie und das Problem der Weltanschaung, en Zur Bestimmung der Philosophie (GA 56/57), Frankfurt am Main, Vittorio Klostermann, 1987 y Heidegger, M.: Einführung in die phänomenologische Forschung (GA 17), Frankfurt am Main, Vittorio Klostermann, 1994; Sartre, J.P.: "Conscience de soi et connaisance de soi", Bulletin de la Société Française de Philosophie, 42, 1948, pp. 49-91; Habermas, J.: Der philosophische Diskurs der Moderne, Frankfurt am Main, Suhrkamp, 1985; Herrmann, F.W.: Hermeneutik und Reflexion. Der Begriff der Phänomenologie bei Heidegger und Husserl, Frankfurt am Main, Vittorio Klostermann, 2000. En las ciencias cognitivas se ha extendido la imagen difundida por Dreyfus ("Husserl's Epiphenomenology", en H.R. Otto y J.A. Tuedio (eds.), Perspectives on Min, Dordrecht, Reidel, 1988, pp. 84-104) у Dreyfus y Hall ("Inroduction", en H.L. Dreyfus y H. Hall (eds.), Husserl, Intentionality, and Cognitive Sciences, Cambridge, MIT Prees, 1982, pp. 1-27) de que Husserl es un solipsista metodológico. En el campo de la filosofía analítica encontramos las críticas de McIntyre ("Husserl and Representational Theory of Mind", Topoi, 5, 1986, pp. 101-113. y Dennett (Consciousness Explained, Boston, Little
} 
gía husserliana -en particular con muchos de los manuscritos publicados póstumamente sobre temas como la intersubjetividad, el tiempo de la conciencia, la síntesis pasiva y la teoría de la asociación- difícilmente puede seguir sosteniendo esta tesis. En contra de algunos de sus críticos, el propio Husserl ya dejó clara la diferencia entre conciencia originaria y reflexión. La conciencia originaria (Urbewußtsein) es primariamente una conciencia no-temática, es decir, una conciencia previa a cualquier tipo de reflexión. Sin esta conciencia originaria no podríamos reflexionar. ${ }^{3} \mathrm{Sin}$ embargo, esta conciencia originaria, por muy fundamental que sea, sólo puede ser descubierta con posterioridad por medio de un acto reflexivo, es decir, la diferencia entre conciencia originaria y reflexión se hace visible gracias a la reflexión.

Este énfasis puesto por Husserl en la reflexión fue arduamente criticado por Heidegger. Desde entonces resulta frecuente encontrarse con la afirmación de que Husserl y Heidegger desarrollan dos conceptos de fenomenología diferentes, incluso antagónicos. Se dice que ambos comparten la máxima fenomenológica de "a las cosas mismas", si bien se distinguen en el modo de acceso y de tratamiento de esas cosas. Nos hallamos, a tenor de un amplio sector de la historiografía filosófica, ante dos conceptos de fenomenología que se diferencian básicamente en la determinación de la intuición fenomenológica: Husserl comprendería esta intuición en términos de un "ver reflexivo"; Heidegger, en cambio, la entendería en términos de una "intuición hermenéutica". Como ha señalado en repetidas ocasiones F.W. Herrmann, la fenomenología de Husserl se determina a partir de una actitud de corte teorético y reflexivo, mientras que la versión heideggeriana de la fenomenología se caracteriza por su dimensión ateorética y prerreflexiva. ${ }^{4}$ Dicho en otras palabras, Husserl se mueve en las coordenadas de una fenomenología reflexiva y Heidegger en las de una fenomenología hermenéutica. ${ }^{5}$

Brown, 1991) y en el de la neurociencia las de Metzinger (Being No One, Cambridge, MIT Press, 2003) y Damasio (Self Comes to Mind. Constructing the Conscious Brain, New York, Pamtheon Books, 2010).

${ }^{3} \mathrm{Cf}$. Husserl HUA IV, p. 318. Al final se ofrece un listado de las abreviaturas de los textos de Husserl.

${ }^{4}$ Cf. Herrmann, F.W.: Der Begriff der Phänomenologie bei Husserl und Heidegger, Frankfurt am Main, Vittorio Klostermann, 1981.Herrmann, F.W.: Wege und Methode. Zur hermeneutischen Phänomenologie des seinsgeschichtlichen Denkens, Frankfurt am Main, Vittorio Klostermann, 1990 y, más recientemente, Herrmann, F.W.: Hermeneutik und Reflexion. Der Begriff der Phänomenologie bei Heidegger und Husserl, Frankfurt am Main, Vittorio Klostermann, 2000.

${ }^{5} \mathrm{La}$ literatura secundaria sobre la relación Husserl-Heidegger es realmente extensa. Con respecto a la cuestión que nos ocupa aquí, a saber, la transformación hermenéutica de la fenomenología, remitimos, junto a los trabajos de Herrmann ya citados, a: Adrian, J.: "Hermeneutische versus reflexive Phänomenologie. Eine kritische Revision Heideggers früher Stellung zu Heidegger ausgehend vom Kriesgnotsemester 1919", Analecta Husserliana LXXXVIII, 2005, pp. 157-173; Fabris, A.: "L'ermeneutica della fatticità nei corsi friburghesi dal 1919 al 1923", en F. Volpi (ed.), Heidegger, Roma, Laterza, 1997, pp. 57-106; Gadamer. H.-G.: Wahrheit und Methode. Grundzüge einer philosophischen Hermeneutik (Gesammelte Werke, Band 1), Tubinga, J.C.B. Mohr, 1986, pp. 258-275; Grondin, J.: Einführung in die philosophische Hermeneutik, Darmstadt, Wissenschaftliche 
Nuestro interés no se centra en seguir alimentando la discusión historiográfica en torno a la legitimidad o la ilegitimidad de esta diferencia, la cual, por cierto, resulta muy útil desde el punto de vista didáctico. Aquí preferimos, por una parte, mostrar el complejo proceso de desarrollo de la fenomenología hermenéutica de Heidegger en el transcurso de sus primeras lecciones de Friburgo (1919-1923) y Marburgo (1924-1928) y, por otra, sopesar algunas de las observaciones críticas de Heidegger a Husserl a la luz de evidencias textuales de la fenomenología husserliana, ignoradas no sólo por Heidegger, sino también por un sorprendente número de reconocidos especialistas en el campo de la filosofía, de las ciencias cognitivas y de la filosofía de la mente.

Así, en el marco de este trabajo se abordan las siguientes cuestiones. En primer lugar, se ofrece una breve panorámica de las etapas de desarrollo de la fenomenología hermenéutica de Heidegger y de sus principales diferencias con respecto a la fenomenología husserliana. En segundo lugar, se expone el núcleo de las observaciones críticas de Natorp y Heidegger al modelo reflexivo empleado por Husserl. En tercer lugar, se replica a la postura de Heidegger. Y, en cuarto lugar, se acotan algunas de las críticas heideggerianas a Husserl, en particular el malentendido ampliamente extendido en la historiografía filosófica en torno al cartesianismo y solipsismo de la fenomenología husserliana. A tal efecto se destacan algunas de las contribuciones más significativas realizadas por la fenomenología genética de Husserl, por lo general ignoradas y que ayudan a deshacer muchos errores de interpretación de su obra.

\section{Irrupción y desarrollo de la fenomenología hermenéutica de Heidegger}

El interés de Heidegger por la fenomenología se remonta a sus primeros artículos de juventud y trabajos académicos como su tesis doctoral sobre el psicologismo y su escrito de habilitación sobre Duns Esoto. ${ }^{6}$ También se sabe que fueron razones financieras las que lo llevaron a estudiar en Friburgo bajo la tutela del neokantiano Heinrich Rickert, en lugar de dirigirse a Gotinga para trabajar al amparo de la tute-

Buchgesellschaft, 1991, pp. 119-137; Kalariparambil, T.: Das befindliche Verstehen und die Seinsfrage, Berlin, Duncker\&Humblot, 1999, pp. 67-148; Merker, B.: Selbsttäuschung und Selbsterkenntnis. Zu Heideggers Transformation der Phänomenologie Husserls, Frankfurt am Main, Suhrkamp, 1988; Pöggeler, O.: Schriften zu einer hermeneutischen Philosophie, Freiburg y Munich, Karl Alber, 1994, pp. 227-247; Rodríguez, R.: La transformación hermenéutica de la fenomenología. Una interpretación de la obra temprana de Heidegger, Madrid, Tecnos, 1997; Xolocotzi, A.: Der Umgang als Zugang. Der hermeneutisch-phänomenologische Zugang zum faktischen Leben in den frühen Freiburger Vorlesungen, Berlin, Duncker\&Humblot, 2002; Zahavi, D.: "How to investigate subjectivity: Natorp and Heidegger on reflection", Continental Philosophy, 36, 2003a, pp. 155-176.

${ }^{6} C f$. Heidegger MWPh, pp. 81-82. Al final se ofrece un listado de las abreviaturas de los textos de Heidegger. 
la académica de Edmund Husserl. Sus primeros escritos académicos se adhieran a la crítica del psicologismo formulada en el volumen primero de las Investigaciones lógicas. Ahora bien, una vez delimitada con nitidez la diferencia entre los actos psíquicos del pensamiento y la validez del contenido lógico del mismo y, por tanto, una vez garantizada la idealidad de la lógica, surge el problema de su fundamentación. La solución de Heidegger apunta hacia la existencia de un contexto translógico, de un previo horizonte significativo desde el que comprender los mecanismos formales del pensamiento humano.

Con todo, el auténtico giro hermenéutico no se producirá hasta el inicio de los primeros cursos de Friburgo, especialmente en las lecciones del semestre de posguerra de 1919, La idea de la fenomenología y el problema de la concepción del mundo. El motivo recurrente de esos cursos es: ¡regreso a la vida en su originalidad! Un motivo en plena consonancia con el clima intelectual de la época que, a nivel filosófico, se traduce en una radicalización del principio de todos los principios de Husserl. A partir de ese momento, Heidegger mantendrá repetidamente que la fenomenología no es ni una disciplina ni un método filosófico entre otros muchos, sino que equivale a la más alta posibilidad de la filosofía misma. ${ }^{7}$ El lema de su propuesta de innovación podría ser el de "contra la fenomenología en nombre de la fenomenología misma".

El desarrollo de la fenomenología hermenéutica pasa por cuatro fases, que se escalonan de la siguiente manera:

- La primera tiene lugar en las mencionadas lecciones de 1919 La idea de la filosofía y el problema de la concepción del mundo, en las que se acomete una primera crítica de los postulados teoréticos de la fenomenología husserliana al mismo tiempo que sientan las bases de la fenomenología hermenéutica a partir del primado de lo preteorético.

- La segunda fase de desarrollo se produce en las lecciones del semestre de invierno de 1923/24, Introducción a la investigación fenomenológica: por una parte, Heidegger ensalza el descubrimiento husserliano de la intencionalidad como constitución fundamental de la conciencia en las Investigaciones lógicas, pero, por otra parte, acusa al Husserl de Ideas I de distanciarse de la fenomenología al interpretar la subjetividad desde el punto de vista el ego cogito cartesiano.

- Este distanciamiento se consuma en una tercera fase en la extensa crítica inmanente a Husserl que encontramos en las lecciones del semestre de verano de 1925, Prolegómenos para la historia del concepto de tiempo, donde Heidegger se posiciona frente a temas clave de la fenomenología

\footnotetext{
${ }^{7}$ Cf., por ejemplo, Heidegger GA 56/57, p. 110; GA 58, p. 139; GA 61, p. 187; GA 63, p. 72; GA 19, p. 9; GA 20, p. 184; GA 21, p. 3; GA 24, p. 1, 3.
} 
husserlina, como la intencionalidad, la conciencia, el ser y la intuición categorial.

- La cuarta y última fase se completa en Ser y tiempo con la elaboración plena del concepto de una fenomenología hermenéutica del Dasein.

Aquí nos interesan sobre todo las fases primera y segunda, en las que Heidegger formula con toda claridad los presupuestos de la fenomenología hermenéutica a la vez que se distancia críticamente de la fenomenología de Husserl, a la que acusa de caer en el idealismo y el solipsismo. ${ }^{8}$ Una acusación que ha hecho fortuna en la historiografía filosófica, en la que se ha instalado una clara diferencia entre la fenomenología reflexiva de Husserl y la fenomenología hermenéutica de Heidegger.

Primera fase. La primera formulación de la fenomenología hermenéutica la encontramos en las lecciones del semestre de posguerra de 1919, La idea de la filosofia y el problema de la concepción del mundo. Estas lecciones se enmarcan en el intento de aprehender temáticamente la experiencia originaria de la vida preteorética y de responder de forma metodológica al esfuerzo por lograr un adecuado acceso a ese ámbito de lo preteorético. La tematización fenomenológica de un nuevo campo de investigación, como el de la vida preteorética, requiere de un nuevo método de análisis. El ámbito de lo preteorético no resulta accesible desde la reflexión y la teoría. La necesidad de hallar un método capaz de aprehender las tramas de significado en las que se da primariamente la vida desemboca en el desarrollo de una fenomenología hermenéutica de la vida fáctica y, por ende, ateorética y preteorética como la que encontramos en las primeras lecciones de Friburgo. Las diferentes formulaciones de esta ciencia originaria de la vida que encontramos en los años posteriores arrancan de esta experiencia originaria y determinan la metodología de la investigación heideggeriana. Por ello, se puede decir que el descubrimiento de la dimensión preteorética de la vida se convierte en el punto arquimédico sobre el que descansa la transformación hermenéutica de la fenomenología y marca el inicio de un camino filosófico que se prolonga durante las lecciones de Friburgo y Marburgo hasta desembocar en Ser y tiempo.

Las mencionadas lecciones del semestre de posguerra de 1919 esbozan todo un nuevo programa filosófico en el que el joven Heidegger se replantea el objeto de estudio y la metodología a emplear. El objeto de estudio es la vida fáctica y el método es la hermenéutica. Tema y método están íntimamente interrelacionados. El método no se reduce a la mera aplicación de una técnica general, sino que debe tener en cuenta el modo de ser del ente temático. Como ya reconoce tempranamen-

8 Para una exposición más detallada de estas cuatro fases, nos permitimos remitir a Adrián, J.: Heidegger y la genealogía de la pregunta por el ser. Una introducción temática y sistemática de su obra temprana, Barcelona, Herder, 2010, pp. 426-525 y Adrian, J.: "El joven Heidegger y los postulados de los prepuestos metodológicos de la fenomenología hermenéutica", Thémata. Revista de Filosofia, 44, 2011, pp. 212-230. 
te Heidegger en las lecciones del semestre de invierno de 1919/20, Problemas fundamentales de la fenomenología, «el método filosófico tienes sus raíces en la vida misma» 9 . Así pues, desde el prisma temático, la filosofía se concibe como ciencia originaria de la vida y de las vivencias. Y a este nuevo enfoque temático le corresponde un peculiar tratamiento metodológico, a saber, la fenomenología hermenéutica, que al igual que la vida y la esfera de las vivencias tiene un carácter esencialmente ateorético y preteorético.

La pregunta que realmente inquieta al joven Heidegger es la de cómo se accede primariamente a esta esfera de la vida preteorética ignorada hasta la fecha por la historia de la filosofía. He ahí la tarea de estas primeras lecciones friburguesas: mostrar la posibilidad y la viabilidad de una fenomenología no reflexiva capaz de delimitar y articular sistemáticamente el ámbito de manifestación de la esfera primaria de la vida humana. Esta esfera primaria permanece inicialmente oculta, distorsionada, desfigurada, desplazada por la incuestionable primacía de la actitud teorética y reflexiva que gobierna la filosofía moderna desde la atalaya del sujeto de conocimiento. De ahí que sea necesario romper con el primado de lo teorético en aras de acceder al suelo originario del que brota la vida en su darse inmediato y captar la vida en su carácter significativo. ¿En qué ámbito se mueve, pues, una ciencia filosóficamente originaria? Heidegger se traslada en las lecciones del semestre de posguerra de 1919 al nivel de la relación primariamente práctica que establecemos con el mundo de la vida. La posibilidad de elaborar un nuevo concepto de filosofía emana de esta relación originaria entre vida y mundo. El origen de toda filosofía se remonta al subsuelo todavía no horadado por la reflexión del mundo de la vida. De entrada, pues, "hay que romper con el predominio de lo teorético". 10

Naturalmente, ese mundo de la vida no es otro que el mundo de lo ateorético y de lo arreflexivo, en definitiva, el mundo simbólicamente articulado en el que ya siempre se encuentra anclada la vida. Se trata de un mundo revestido del manto de la significatividad, un mundo al que accedemos de una manera directa a través de cierto grado de familiaridad con él, que nos resulta ya siempre comprensible de un modo u otro. Un mundo, por tanto, que se nos abre hermenéutica y no reflexivamente: «en lugar de conocer cosas, hay que comprender mirando y mirar comprendiendo» ${ }^{11}$. No se niega el conocimiento en general, sólo la primacía otorgada infundadamente al conocimiento de tipo teorético y objetivante. El conocimiento del mundo de la vida se basa en un mirar ateorético, en un comprender no reflexivo. El conocimiento preteorético que adquirimos a partir de nuestro contacto directo con el mundo de la vida se condensa en la comprensión y no tanto en la explicación. Esto no significa que el acceso reflexivo a la esfera de las vivencias sea falso o erró-

\footnotetext{
${ }^{9}$ Heidegger GA 58, p. 228.

10 Heidegger GA 56/57, p. 59.

11 Heidegger GA 56/57, p. 65.
} 
neo. Simplemente es un modo derivado, es un acto de segundo orden que sólo es posible a partir de la comprensión previa, atemática y prerreflexiva del mundo inmediato de la vida y de las vivencias.

La segunda parte de las lecciones de 1919 La idea de la filosofía y el problema de la concepción del mundo muestra como la realización filosófica de una ciencia originaria de la vida está íntimamente relacionada con una transformación hermenéutica de la fenomenología. Heidegger se interroga: ¿cómo experimentamos la vida, cómo aprehendemos la realidad antes de toda consideración científica, observación valorativa o concepción del mundo? De entrada se invoca el principio de todos los principios según el cual «todo lo que se manifiesta originariamente en la 〈intuición〉 se ha de tomar simplemente [...] como lo que se da» ${ }^{12}$, para añadir a continuación que la aplicación que hace el propio Husserl de ese principio se limita a la descripción de los diferentes modos de darse las cosas a una conciencia orientada únicamente de forma teorética. Heidegger replica que en las vivencias que tenemos en nuestro mundo circundante raras veces nos comportamos siguiendo un patrón teorético. La actitud originaria de la vivencia no es de este tipo. Para ilustrar este cambio de perspectiva Heidegger ofrece una densa descripción fenomenológica de una vivencia inmediata de nuestro entorno más familiar y cotidiano como la vivencia de «ver una cátedra». 13

El ejemplo de la vivencia del mundo circundante de la cátedra ilustra el modo originario de darse las cosas. Éstas no se manifiestan primariamente en la región interior de la conciencia según el esquema tradicional de sujeto-objeto; antes bien, nos resultan accesibles y comprensibles desde el horizonte de precomprensión del mundo inherente a la vida misma. Las vivencias del mundo circundante no arrancan de la esfera de objetos colocado ante mí y que percibo, sino del plexo de útiles de los que me cuido y comprendo. No es que primero veamos colores, superficies y formas de un objeto para asignarle más tarde un significado; en realidad, de alguna manera ya comprendemos las cosas gracias a nuestra familiaridad con el mundo en el que habitualmente vivimos. La cátedra se da inicialmente en un contexto significativo como el aula académica de la universidad y sólo después se percibe con sus cualidades objetivas como el color, la forma, la ubicación, el peso, etcétera. Efectivamente, si pensamos sobre el acto de "ver la cátedra", pasamos de repente a otro orden, que ya no es el del percibir. En el orden de la percepción todavía pensamos según el modelo de sujeto y objeto: existe un yo que percibe un objeto con diferentes propiedades. Heidegger argumenta que al entender la percepción como la experiencia privada de un sujeto aislado se corre el riesgo de un individualismo metodológico que distorsiona por completo nuestras vivencias inmediatas del mundo.

\footnotetext{
12 Heidegger GA 56/57, p. 109 [cursiva del autor]

13 Cf. Heidegger GA 56/57, pp. 70-73.
} 
El ejemplo de la cátedra pone de manifiesto que la vida humana vive esencialmente en horizontes de significatividad. El mundo condensa la totalidad de significaciones desde la que se comprenden las situaciones, cosas y personas que comparecen en el trato cotidiano con el mundo circundante de la vida. La percepción y el conocimiento no sólo significan percepción de algo y conocimiento de algo, sino percepción y conocimiento en un mundo, en un horizonte. Este horizonte significativo es anterior a todo acto de percepción y conocimiento, puesto que ya todo acto lo presupone y pone en juego tácita o expresamente.

En definitiva, con el reconocimiento de la referencia al mundo (Weltbezogenheit), de la significatividad (Bedeutsamkeit) y de la autosuficiencia (Selbstgenügsamkeit) como elementos constitutivos de la vida fáctica se consuma en el joven Heidegger un cambio radical de perspectiva: se pasa del paradigma de la percepción de la filosofía de la conciencia al paradigma de la comprensión de la hermenéutica. Decididamente, nos hallamos ante dos formas del "ver fenomenológico": una desde la actitud teorética de la fenomenología husserliana y otra desde la actitud ateorética de la hermenéutica heideggeriana. ${ }^{14}$

Segunda fase. El segundo momento de distanciamiento crítico con respecto a la fenomenología husserliana se produce en las lecciones del semestre de invierno de 1923/24, Introducción a la investigación fenomenológica, en el marco de una intensa discusión con Descartes. Heidegger no comparte la simpatía que Husserl muestra por el modo de pensar de la matemática como una vía de acceso a la pureza de la conciencia. En este sentido, la fenomenología se orienta por el ideal de exactitud de las matemáticas, decisión que precisamente Heidegger critica con severidad. Esta manera de proceder no deja ver las cosas mismas, sino que las distorsiona desde el prisma de la subjetividad reflexiva. Con mayor rotundidad que en los primeros cursos de Friburgo, Heidegger afirma que el criterio de la evidencia que maneja Husserl está determinado por el "predominio de una idea de certeza vacía y por ello fantástica". ${ }^{15} \mathrm{La}$ adhesión husserliana a la noción de evidencia está motivada por la preocupación por un conocimiento absoluto que encaja con su idea de una fenomenología como ciencia estricta libre de todo presupuesto. La meta final es "asegurarse y fundar una cientificidad absoluta"16, que se inspira en el ideal de conocimiento matemático defendido por el programa cartesiano. Pero de esta manera, las cosas no se muestran desde sí misma, sino desde la imposición de un determinado tipo de conocimiento con pretensión de certeza absoluta como el conocimiento físico-matemático. A juicio de Heidegger, el procedimiento husserliano

\footnotetext{
14 Y, como se verá más adelante, a estas dos formas de "ver" les corresponden dos formas de acceso fenomenológico: la del método de la reflexión descriptiva de Husserl y la del método de la comprensión hermenéutica de Heidegger.

15 Heidegger GA 17, p. 43.

16 Heidegger GA 17, p. 72.
} 
"absolutiza la idea de un tratamiento científico de la conciencia". ${ }^{17}$ Esto significa que se antepone el criterio de cientificidad, con lo cual ya no se deja que las cosas se manifiesten desde sí mismas tal y como reza la máxima fenomenológica. El excesivo énfasis puesto en la preocupación cartesiana por la certeza desfigura algunos de los hallazgos fenomenológicos de Husserl, en particular el de la intencionalidad. La intencionalidad queda desfigurada en el momento en que se la comprende como un comportamiento primordialmente teorético que condiciona el modo de ver y de analizar los actos intencionales. 18

En definitiva, la fenomenología hermenéutica que plantea Heidegger pretende romper con el ideal husserliano de una filosofía como ciencia estricta, exenta de presupuestos, transparente y neutra. El principio de neutralidad valorativa que encabeza la fenomenología husserliana se asienta en dos presupuestos: la exclusión de toda teoría previa y el criterio de la evidencia fenomenológica. ${ }^{19}$ Heidegger asume este último criterio metodológico hasta tal punto que lo vuelve contra su propio maestro. Husserl aplica el modelo de la actitud teorética sin una justificación preliminar, lo que a los ojos de Heidegge ya constituye una decisión previa, por tanto, un prejuicio. ${ }^{20} \mathrm{El}$ acceso fenomenológico a las vivencias de Husserl se realiza desde el prisma de una representación subjetiva de procesos objetivos que responde al modelo de la actitud teórica. Sin embargo, el análisis heideggeriano de las vivencias del mundo circundante arroja un resultado bien diferente. El sentido originario de las vivencias difiere ostensiblemente del conocimiento teórico que ofrece la reflexión objetivante.

La teoría no es la actitud natural del pensamiento, sino que encarna una determinada posición. A partir del descubrimiento del carácter posicional de la teoría, Heidegger establece la distinción entre actitud fenomenológica y teorética. La teoría desdobla la vida en el hecho mismo de vivir y en la mirada refleja de ésta. El énfasis puesto en la teoría distorsiona nuestro acceso al mundo al desmenuzar la esfera primaria de las vivencias ante la mirada cosificadora del sujeto, esto es, falsea nuestras vivencias inmediatas al extirparlas artificialmente del mundo de la vida del que emergen. ${ }^{21}$ Se pasa así de la conciencia reflexiva husserliana, que de mane-

\footnotetext{
17 Heidegger GA 17, p. 71. Este modo de tratamiento de las vivencias provoca una paralización y objetivación de la corriente vital de la conciencia. La descripción de una cosa ya siempre es la cosa representada. La misma descripción fenomenológica, por muy inmediata que sea, se realiza sobre una cosa representada y previamente comprendida. De hecho, ésta es una de las principales objeciones que Natorp ya realizara a Husserl tras la publicación de Ideas I. A juicio de Natorp, hay que disolver el estricto dualismo de conciencia y objeto e insistir en su íntima correlación partiendo de la potencia primordial de la vida. En el siguiente apartado se explica con más detalles las críticas de Natorp.

18 Cf. Heidegger GA 17, p. 271.

19 Cf. Husserl HUA XIX/1, p. 24; Husserl, Philosophie als strenge Wissenschaft, pp.340-341.

20 Cf. Heidegger GA 63, p. 83.

${ }^{21}$ Merece la pena recordar que "teorético" no alude en Heidegger a esta o aquella teoría, sino que significa en sentido literal: "contemplar", "observar" (betrachten). A la observación la pertenece la dis-
} 
ra intuitiva tiene ante sí su objeto, a lo que Heidegger llama la "situación hermenéutica". Ésta precede a la mirada, mejor dicho, está indisociablemente presente en ella y forma parte de ella. La mirada fenomenológica debe dirigirse de manera directa a la vida fáctica misma. El acto filosófico que facilita la apropiación de la vida y que, por tanto, hace expresa la vivencia originaria pasa por un determinado tipo de intuición: la intuición hermenéutica. Con la apropiación de la situación hermenéutica

\section{Las observaciones críticas de Natorp y la respuesta de Heidegger}

A poco tiempo de la publicación de Ideas I (1913) Natorp redactó una reseña del libro de Husserl en la que se muestra crítico frente a la posibilidad de investigar el ámbito de la subjetividad en términos reflexivos. ${ }^{22}$ A su juicio, existe una diferencia radical entre sujeto y objeto. El objeto resulta accesible por medio de una descripción y explicación teoréticas; el sujeto, en cambio, se manifiesta como aquello opuesto a todo objeto (Gegen-stände). Mientras que cualquier cosa puede convertirse en un objeto para la conciencia, no sucede lo mismo con el sujeto. En su Psicología general (1912) señala que en el momento en que empezamos a pensar reflexivamente en el sujeto como un objeto dejamos de pensar en el sujeto como un sujeto. ${ }^{23}$ Esto no implica el abandono del uso de la reflexión, pero sí tomar conciencia de que la reflexión es un prisma que distorsiona las vivencias inmediatas del sujeto. La reflexión nos coloca delante de una subjetividad objetivada. Y este acto reflexivo no debe confundirse con la subjetividad misma que realiza ese acto. El yo no es un dato; no es algo dado. Si el yo estuviera dado, estaría dado para alguien, es decir, se convertiría en un objeto y, por ello, ya no sería un yo. ${ }^{24}$ Queda claro, pues, que el interés de Natorp no se centra tanto en la psicología empírica como en la investigación transcendental de la subjetividad.

Ahora bien, ¿cómo se puede llevar a cabo una investigación de este tipo? De hecho, si la subjetividad ha de ser investigada ésta tiene que expresarse de alguna manera: bien por medio del lenguaje o bien por medio del comportamiento. Pero toda expresión (Äußerung) es, de acuerdo con Natorp, una externalización (Entäußerung). En otras palabras, en el momento en que la conciencia se expresa ella misma abandona su propio dominio de donación inmediata y entra en el reino de los objetos. ${ }^{25}$ De ahí que resulte imposible aprehender conceptual y reflexiva-

tancia hacia lo observado. A través de esta modificación reflexiva, la vivencia pierde su fuerza de realización vital. Hay que dar un paso atrás y tomar conciencia de que la teoría y la reflexión arrancan de lo dado inmediatamente de una manera preteorética y ateorética en el mundo de la vida.

22 Cf. Natorp, P.: "Husserls Ideen einer reinen Phänomenologie", Logos, 7, 1917/18, pp. 215-240.

${ }^{2}$ Cf. Natorp, P.: Allgemeine Psychologie,Tübingen, J.C.B. Mohr, 1912, p. 31.

24 Cf. O.c., p. 40.

25 Cf. O.c., p. 99. 
mente la conciencia sin objetivar la subjetividad y sin detener el fluir de la vida misma. Esta es una de las principales objeciones que Natorp realizara a Husserl tras la publicación de Ideas I: el hecho de que toda vivencia, en cuanto expresada en conceptos, queda objetivada y se somete a un proceso de homogeinización que disuelve la particularidad concreta de toda vivencia. ${ }^{26}$ La subjetividad pura que se manifiesta como residuo fenomenológico tras la reducción precisa de un complejo esfuerzo de abstracción que detiene la corriente vital de las vivencias. Asimismo, la aplicación del modelo de conocimiento matemático, que arranca de Platón y encuentra su máxima expresión en Descartes, no llega a captar el movimiento fluctuante de la vida en su darse inmediato; es más, los conceptos fijan esa realidad y provocan una modificación reflexiva de la corriente de las vivencias. El trato científico de las vivencias les roba a éstas, por decirlo así, su carácter de vivencia. Pero, como señala Natorp, "la corriente en el fluir es algo diferente a lo que se aprehende y retiene en la reflexión". ${ }^{27}$

¿Significa esto caer en el escepticismo y negar la posibilidad de una investigación sistemática de la subjetividad? La respuesta es no. Natorp sugiere una estrategia diferente. De entrada, Natorp da por hecho que no tenemos un acceso directo a nuestra propia subjetividad originaria y que en la reflexión sólo aprehendemos un sujeto paralizado y objetivado. Por mucho que mejoremos la capacidad de investigar los objetos nunca llegaremos a aprehender nuestra subjetividad. Dicho de una manera más gráfica, por mucho que afilemos un cuchillo, éste nunca será capaz de cortarse a sí mismo. Pero, entonces, ¿qué otras posibilidades tenemos a nuestro alcance? Para alcanzar la subjetividad tenemos que efectuar un proceso de purificación, tenemos que neutralizar el efecto paralizador de la reflexión. Esto es, después de haber analizado y, por tanto, objetivado la unidad viva de la conciencia tenemos que intentar revertir el proceso, tratar de unir los elementos desgajados y, finalmente, restaurar la vivencia en su estado originario. ${ }^{28}$ Natorp habla de la aplicación de un método de reconstrucción que, ante la imposibilidad de investigar directamente nuestra subjetividad, procede de una manera regresiva en un intento por recuperar nuestra originaria dimensión subjetiva. Con todo, la posibilidad de alcanzar la dimensión pura de la subjetividad es un ideal inalcanzable.

En el ya mencionado curso de 1919, La idea de la filosofía y el problema de la concepción del mundo, Heidegger se hace eco de una buena parte de las críticas de

\footnotetext{
${ }^{26}$ Cf. Natorp: "Husserls Ideen einer reinen Phänomenologie", ed. cit., pp. 215-240.

27 Natorp: "Husserls Ideen einer reinen Phänomenologie", ed. cit., p. 231. De ahí que, según su opinión, no sea posible un trato con las vivencias en su inmediatez, pues lo inmediato ya siempre está mediado por conceptos. Como se señala a continuación, Heidegger asume buena parte de las observaciones críticas de Natorp y valora positivamente su insistencia en el carácter dinámico y cinético de las vivencias.
}

28 Cf. Natorp: Allgemeine Psychologie, ed. cit., p. 192. 
Natorp a Husserl. ${ }^{29}$ Heidegger observa que Natorp es el único que ha sido capaz de formular objeciones científicamente relevantes contra la fenomenología husserliana. Sus críticas se concentran en dos aspectos. Por una parte, la fenomenología afirma describir y analizar la subjetividad vivida misma. Y para ello emplea una metodología reflexiva. Pero la reflexión es una actitud teorética que desemboca en una objetivación. Y, por otra parte, la fenomenología presume describir las vivencias en su inmediatez preteorética. Sin embargo, toda descripción implica el uso del lenguaje y el uso de conceptos generales. Por esa misma razón, toda descripción y expresión implican una mediación y una objetivación que nos distancian de la subjetividad misma.

En sintonía con Natorp, Heidegger señala que la reflexión es una actitud teorética. Asimismo, toda empresa teorética y toda observación envuelven cierta modificación objetivante, cierta privación de vida (Entlebung) que introduce una fractura entre la vivencia y lo vivenciado. ${ }^{30}$ Esta modificación es particularmente intensa en el caso de la reflexión, la cual convierte una vivencia no vivida reflexivamente en un objeto observado. Pero a pesar de este acuerdo básico, Heidegger no comparte el método reconstructivo propuesto por Natorp. La llamada reconstrucción es ella misma una construcción, es decir, un procedimiento toerético y objetivante. Resulta, pues, difícil comprender como un procedimiento de este tipo puede lograr acceder la esfera inmediata de la vida subjetiva. ${ }^{31}$

Ahora bien, la pregunta que se formula Heidegger es si la fenomenología tiene que ser necesariamente reflexiva. ¿Hay acaso otro modo de acceder a la donación inmediata de la vida? A su juicio, sí. Y ese modo se consuma, como hemos mostrado anteriormente, en una actitud pre-teorética, en una comprensión pre-reflexiva que él denomina "intuición hermenéutica". 32 En opinión de Heidegger, la vida y sus vivencias no son un objeto. 33 Por la misma razón sería un grave error investigar la vida utilizando el mismo método empleado por las ciencias positivas. La ciencia que investiga la vida es un tipo de ciencia diferente de la que se encarga de describir el mundo de los objetos: se trata de una ciencia peculiar, de una ciencia capaz de aprehender el originario nivel de manifestación de la vida. Esa ciencia, encarna-

29 Cf. Heidegger GA 56/57, pp. 99-108. Y en las lecciones del semestre de verano de 1920, Fenomenología de la intuición y de la expresión, se puede encontrar un extenso apartado dedicado a la posición de Natorp ( $c f$. GA 59, pp. 92-147).

30 Cf. Heidegger GA 56/57, pp. 73-74.

31 Cf. Heidegger GA 56/57, pp. 104, 107. Es más, dado que Natorp niega que la vida subjetiva esté dada previa al análisis, su método reconstructivo carece de un principio fiable, de un criterio que permita determinar si realmente se ha logrado alcanzar la dimensión originaria de la vida.

32 Cf. Heidegger GA 56/57, p. 117.

33 Cf. Heidegger GA 58, p. 145. Pero el hecho de que la vida no sea un "objeto" no debe llevarnos a inferir erróneamente que sea un "sujeto", pues tanto la objetivación como la subjetivización son dos modos de deformación teorética de la vida ( $c f$. GA 58, pp. 145-147). 
da paradigmáticamente por la fenomenología, recibe en las primeras lecciones de Friburgo del joven Heidegger el nombre de una "ciencia originaria de la vida". De ahí que cuando se estudia el ámbito de la vida y de sus vivencias resulte estéril aplicar las categorías tradicionales de "interior" y "exterior", "subjetivo" y "objetivo", "inmanencia" y "trascendencia". Así queda claro que cuando Heidegger habla de vida (Leben) y vivencias (Erlebnisse) no se está refiriendo a entidades psicológicas. Interpretar vivencias en términos de procesos psicológicos y fisiológicos ya es un acto de objetivación. ${ }^{4}$ Incluso el mismo término de "vivencia" (Erlebnis) está tan cargado que resultaría mejor evitarlo. Pero, como apunta Zahavi, en 1919 Heidegger todavía piensa que este es el mejor término disponible. 35

¿Cuál es entonces el punto de partida del análisis heideggeriano? Simple y llanamente la experiencia fáctica de la vida misma, caracterizada por su peculiar estructura hermenéutica, autocomprensión y autosuficiencia. En contra del punto de vista expuesto por Natorp, Heidegger afirma que la articulación y conceptualización fenomenológicas de la vida es algo que pertenece a la vida misma. Así, una verdadera descripción fenomenológica de la vida no constituye un acto de deformación, sino que más bien es algo que está anclado en y motivado por la misma vida fáctica. La fundamental familiaridad que la vida guarda consigo misma y su capacidad de autointerpretarse no adopta la forma de una comprensión reflexiva, ni de una auto-observación temática; tampoco envuelve ningún tipo de auto-objetivación. Al contrario, asistimos a un proceso de autoconocimiento de la vida de carácter preteorético (es decir, que no precisa de la realización de un explícito ejercicio reflexivo y que debe comprenderse como una expresión inmediata de la vida misma). ${ }^{36}$ Cuando investigamos la vida fáctica la articulamos y, de esta manera, la modificamos. En el mejor de los casos, esta articulación emana de la vida misma y está motivada por ella misma.

\section{Una posible réplica a Heidegger: ¿reflexión como atención?}

La pregunta que cabe plantearse una vez expuesta la crítica heideggeriana sobre el carácter reflexivo de la fenomenología husserliana puede formularse de la siguiente manera: ¿Hasta qué punto se pueden sostener las objeciones de Heidegger? A pesar de que Heidegger comparte ampliamente las críticas de Natorp a la fenomenología reflexiva, ello no es prueba suficiente de que su propia alternativa hermenéutica sea realmente no-reflexiva. De hecho, existen buenas razones para creer que la intuición hermenéutica de Heidegger no es otra cosa que un tipo

34 Cf. Heidegger GA 56/57, pp. 65-66.

35 Cf. Zahavi, D.: "How to investigate subjectivity: Natorp and Heidegger on reflection", Continental Philosophy, 36, 2003a, p. 161.

36 Cf. Heidegger GA 58, pp. 159, 257-258. 
no-objetivante de reflexión. En este sentido, resulta interesante recordar la diferencia que Sartre establece en El ser y la nada entre la reflexión pura y la reflexión impura. ${ }^{37}$ Al igual que Natorp y Heidegger, Sartre también coincide en que todo proceso de objetivación encierra una transformación distorsionante del fenómeno investigado. Sus críticas a la reflexión se enmarcan en su defensa de una teoría noegológica de la conciencia. ${ }^{38}$ De acuerdo con él, la conciencia pre-reflexiva no tiene una estructura egológica. En otras palabras, mientras vivimos una vivencia, mientras estamos absortos en ella no hay señales de un ego reflexivo. Esto sólo sucede cuando adoptamos una actitud distanciadora y objetivante respecto a la vivencia en cuestión, esto es, cuando reflexionamos sobre ella. Esto se manifiesta de una manera muy clara en los fenómenos de ruptura y disfuncionalidad.

Nadie niega que la existencia de formas de reflexión que son objetivantes, pero en última instancia la cuestión es si resulta apropiado reconocer la existencia de una forma de reflexión que consista en un simple mirar y tomar las cosas tal como se dan. Sin embargo, ¿por qué no simplemente comprender la reflexión fenomenológica como una forma especial de atención? ${ }^{39}$ En un pasaje de Fenomenología de la conciencia interna del tiempo Husserl escribe que la vivencia sobre la que fijamos nuestra atención en la reflexión adquiere un nuevo modo de ser: deviene acentuada. ${ }^{40}$ Desde este punto vista la reflexión no es otra cosa que una intensificación o acentuación de la vivencia primaria. Husserl también observa que la reflexión es un proceso que abre, desenreda, articula todos aquellos componentes y aquellas estructuras que estaban implícitamente contenidos en la vivencia vivida. 41

Retomando las palabras del propio Heidegger acerca de la naturaleza hermenéutica de la vida, cabe decir que ésta no es caótica e irracional, sino que posee una articulación interna. Por tanto, no se debe confundir la unidad fluctuante de nuestras vivencias con una carencia de forma o falta de estructura. Al contrario, nuestras vivencias poseen una estructura significativa. Precisamente esto es lo que las hace accesibles a la reflexión y a la articulación conceptual. Esta articulación no se impone de manera necesaria desde fuera, ni representa una distorsión, sino que también se puede considerar como una consumación de la vivencia. En palabras de Husserl, al principio estamos confrontados con una vivencia muda que después, por medio de reflexión, puede ser articulada. ${ }^{42}$

37 Cf. Sartre, J.P.: L'être et le neánt. Essais d'ontologie phénoménologique, Paris, Gallimard, 1943, p. 145 .

38 De una manera similar a Heidegger, Sartre afirma que el campo transcendental del que habla la fenomenología de Husserl debe ser caracterizado como impersonal, mejor dicho, prepersonal.

$39 C f$. Zahavi, D.: "How to investigate subjectivity: Natorp and Heidegger on reflection", Continental Philosophy, 36, 2003a, p. 170.

40 Cf. Husserl HUA X, p. 129.

${ }^{4}$ Cf. Huserl HUA X, p. 128; HUA XI, p. 205; HUA XXIV, p. 224.

42 Para más información, véase Liangkang, N.: "Urbewusstsein und Reflexion bei Heidegger", Husserl Studies, 15, 1998, pp. 79-84. 
La reflexión descriptiva es el método empleado tanto en Investigaciones lógicas como en Ideas I. Cotidianamente, vivimos en nuestros actos, pero no reflexionamos sobre ellos. Para que se conviertan en objetos intencionales hay que romper con la absorción inmediata en la vida prerreflexiva o prefenomenológica. El tránsito de la actitud prefenomenológica a la fenomenológica se produce por medio de la reflexión. Mediante la reflexión, como explica Husserl en la "Quinta Investigación", se produce una modificación de la vivencia por la que pasamos del acto al objeto intencional. $43 \mathrm{Al}$ reflexionar no sólo vemos la vivencia como objeto intencional, sino que también se da la posibilidad del conocimiento. En Ideas I se dice con claridad que "sólo por medio de actos de experiencia reflexiva sabemos algo de las corrientes de las vivencias y de la necesaria referencia de ellas al yo puro". ${ }^{44}$ Sólo lo que se somete a la modificación reflexiva puede ser cognoscible. Es evidente que tenemos conciencia de nuestras vivencias concretas, pero sólo la reflexión permite un saber explícito de ellas. Cuando, por ejemplo, monto en bicicleta, estoy dirigido a la carretera, al tráfico que me rodea, al manillar y a los frenos, pero no veo el acto "montar en bicicleta" como tal. Sólo al bajar de la bicicleta y al dirigir la mirada a la vivencia experimentada mediante otra vivencia, la vivencia reflexiva, aparece el "montar en bicicleta" como acto. Se pasa así de una vivencia de primer grado, atemática y simplemente intuida, a una de segundo grado: la vivencia reflexiva que transforma la inmediata en objeto intencional del yo. 45

La fenomenología insiste en que la autoconciencia no se puede reducir a un autoconciencia reflexiva, temática, conceptual y mediada. Por el contrario, la autoconciencia reflexiva presupone una autoconciencia pre-reflexiva, a-atemática, tácita, a-conceptual, inmediata. Es principalmente Sartre quien estableció esta distinción entre autoconciencia reflexiva y pre-reflexiva. De esta manera, la principal distinción que cabe realizar es la distinción entre el caso en que un objeto se da conscientemente de manera objetiva y el caso en que la conciencia misma se da forma auto-consciente. En otras palabras, la conciencia no sólo se da cuando reflexionamos sobre ella, sino que ya está dada antes de toda reflexión. La donación en primera persona no debería tomarse como resultado de una representación de orden superior, reflexión o introspección, sino más bien considerarse como una cualidad intrínseca de las vivencias que incluye la cualidad de mío (Meinheit). Como Husserl afirmó en sus famosas lecciones sobre la conciencia interna del tiempo, una experiencia es consciente de sí misma en el mismo momento de su manifestación. ${ }^{46}$

\footnotetext{
43 Cf. Husserl HUA XIX/1, p. 357.

44 Husserl HUA III/1, p. 168.

45 Cf. Husserl HUA III/1, pp.177-178. Esta determinación de la modificación de la conciencia que permite aprehender reflexiva y objetivamente cualquier vivencia atemática es la que Heidegger tiene presente en las lecciones de 1919, cuando critica la naturaleza teorética de la reflexión como responsable de un proceso de cosificación de las vivencias inmediatas del mundo circundante.

46 Sin embargo, hablar de autoconciencia pre-reflexiva no es lo mismo que hablar de una autoconciencia temática y explícita (cf. Sartre, J.P.: La transcendance de l'ego, Paris, Vrin, 1936, pp. 23-24). La
} 
Asimismo, hemos visto que Heidegger distingue entre reflexión objetivante y tematización no objetivante, entre reflexión y hermenéutica. Sin embargo, muchos fenomenólogos no dudarían en realizar la misma distinción, pero insistirían que se trata de una distinción entre dos tipos diferentes de reflexión: uno objetivante y otro no objetivante. En este sentido, como señala acertadamente Zahavi, resulta razonable afirmar que lo que hace Heidegger es describir con mayor detalle este último tipo de reflexión. Así, la verdadera contribución de Heidegger consistiría en haber prestado una atención especial a este tipo peculiar de reflexión no objetivante; un tipo de reflexión que nos provee con un acceso a la subjetividad viva que resiste la crítica de Natorp. ${ }^{47}$ En la medida en que la fenomenología hermenéutica busca tematizar y articular estructuras vivenciales no hace otra cosa que llamar nuestra atención sobre algo en lo que normalmente vivimos, pero que por lo general no tomamos en cuenta debido a nuestra absorción en el mundo cotidiano que nos rodea. Aquí la reflexión se entiende como una forma de atención. La transición de una forma a otra puede comprenderse en términos de una modificación atencional. 48 Como apunta Crowell, la intuición hermenéutica es más una reapropiación que un rechazo de lo concepto genuinamente fenomenológico de reflexión. ${ }^{49}$ Desde este punto de vista, la radical distinción establecida por Heidegger entre fenomenología reflexiva y fenomenología hermenéutica pierde parte de su fuerza argumentativa una vez se toma en consideración el conjunto de las aportaciones de la fenomenología de Husserl.

autoconciencia en cuestión bien puede ir acompañada de una ignorancia fundamental. Si bien no puedo ser inconsciente de mi vivencia presente, puedo decidir ignorarla para centrarme en su objeto. De hecho, esto es lo que hacemos habitualmente. En mi vida cotidiana, estoy por lo general absorto en mis quehaceres y preocupado por mis proyectos, apenas prestando atención a mis vivencias como tales, esto es, la autoconciencia pre-reflexiva no debe entenderse tanto en términos de una total autocomprensión de mí mismo como de un pre-comprensión que permite llevar a cabo una reflexión o tematización ulteriores.

47 Cf. Zahavi, D.: "How to investigate subjectivity: Natorp and Heidegger on reflection", Continental Philosophy, 36, 2003a, p. 170.

48 Con todo, no se pueden pasar por alto las diferencias entre atención y reflexión. Como señala Husserl tanto en Investigaciones lógicas como en Ideas I, la atención es un rasgo particular de nuestros actos primarios, es decir, no es un acto nuevo ( $c f$. Husserl HUA XIX, p. 425; HUA III/1, p. 75 76). Prestar atención a algo no significa iniciar dos procesos o actividades distintas, sino modificar uno y el mismo acto. La reflexión, por el contrario, es un acto nuevo y fundado.

49 Cf. Crowell, S.G.: Husserl, Heidegger, and the Space of Meaning. Evanston: Northwestern University Press, 2001, p. 137. 


\section{Acotaciones a la interpretación heideggeriana y aportaciones de la fenome- nología genética de Husserl}

\subsection{La cuestión del solipsismo y la teoría de la constitución}

Se ha convertido en un hábito tildar a la fenomenología husserliana de solipsista; un hábito respaldado con frecuencias por las críticas de Heidegger y Sartre. Pero, como es sabido, Heidegger y Sartre basaron sus críticas en la fenomenología transcendental expuesta en Ideas I. Hoy en día, a la luz de la nueva evidencia textual proporcionada por la publicación de la obra póstuma de Husserl, resulta difícil sostener esta crítica. Así, por ejemplo, en las investigaciones sobre la síntesis pasiva y la intersubjetividad queda claro que el punto de partida de la fenomenología no es la conciencia en su polaridad noético-noemática estática, sino la vida en el proceso de autoconstitución de su temporalidad inmanente y de su historicidad propia como constitución progresiva de sentido. El sujeto humano sólo tiene sentido en plural como parte integrante de una intersubjetividad abierta. ${ }^{50}$ En contra de las tradicionales críticas formuladas por Heidegger y Sartre, retomadas ampliamente por los manuales de filosofía, la experiencia no comienza con un ego solipsista que, en pasos sucesivos, constituye al otro y los objetos, sino que arranca de un conjunto de estratos de significación y habitualidades previas generadas por medio de un previo proceso de síntesis pasivas.

Por tanto, ¿puede todavía sostenerse esta acusación? ¿Es Husserl realmente un defensor del solipsismo? ¿No nos hallamos ante una sobresimplificación profundamente incrustada en la historiografía contemporánea, tanto en la tradición analítica como en la continental? ¿Es realmente cierto que la fenomenología clásica se basa en la introspección? Consideremos, por ejemplo, las Investigaciones lógicas, donde Husserl rechaza abiertamente el psicologismo y defiende la necesidad de una clarificación epistemológica de la relación entre conceptos e intuición. Aquí no se recurre a ningún método introspectivo. A pesar de que la fenomenología está interesada en los fenómenos y en cómo las cosas están dadas al sujeto en la vivencia, cualquier fenomenólogo afirmaría que es una falacia metafísica localizar el reino fenoménico dentro de la mente y negaría que el modo de acceder y describir los fenómenos se realice por medio de la introspección. Con frecuencia se asume que el fenómeno es algo meramente subjetivo, un velo que oculta la realidad objetivamente existente. Sin embargo, los fenomenólogos tienen una comprensión diferente de lo que un fenómeno es.

\footnotetext{
50 Como ha mostrado Zahavi, la forma de una comunidad intermonádica es el verdadero punto de partida de una filosofía transcendental. Sólo por medio de una abstracción unilateral se puede hablar de un ego encapsulado ( $c f$. Zahavi, D.: Husserl and Transcendental Intersubjectivity. A Response to the Linguistic-Pragmatic Critique, Athens, Ohio University Press, 2001, pp. 2-24).
} 
Así, por ejemplo, en relación con la percepción del mundo, uno no realiza un ejercicio introspectivo de representación perceptiva, sino que simplemente percibe el mundo tal como se manifiesta. En lugar de decir que experimentamos representaciones, resultaría más adecuado decir que nuestras vivencias son presentacionales, que presentan el mundo revestido de ciertos rasgos. Si alguien me preguntara si está lloviendo fuera, miraría a través de la ventana antes que en mi mente. Reportes en primera persona de este tipo no son reportes introspectivos, si concebimos introspección como una cuestión de conciencia reflexiva. Como Sartre señala plásticamente en El ser y la nada, "una mesa no está en la conciencia, ni siquiera como representación. Una mesa está en el espacio, cerca de la puerta. (...) El primer paso de la filosofía es expulsar las cosas de la conciencia y restablecer la verdadera relación entre éstas y el mundo". ${ }^{51}$ Dicho de otra manera, si alguien me preguntara “¿Ves la mesa?”, podría contestar afirmativa o negativamente, sin iniciar un proceso reflexivo de segundo orden que tomara mi propia vivencia como un objeto. En cambio, si la pregunta fuera "¿Qué te dice la mesa?", probablemente me vería obligado a adoptar una actitud reflexiva en la medida en que la pregunta en cuestión rompe con mi habitual vivencia visual, táctil o incluso olfativa de una mesa.

En diferentes ocasiones, Hubert Dreyfus ha afirmado a partir de su lectura de Heidegger que la fenomenología transcendental de Husserl incurre en una especie de solipsismo metodológico de que la fenomenología husserliana es una empresa exclusivamente interesada en la representación mental que permanece en la conciencia después de llevar a cabo la reducción. 52 Ahora bien, resulta altamente problemático ofrecer una interpretación aislada de la teoría husserliana de la intencionalidad sin tener en cuenta la teoría de la reducción y de la constitución. Afirmar que Husserl cancela toda preocupación por el mundo exterior para concentrarse exclusivamente en la estructura interna de la vivencia, afirmar que la reducción fenomenológica implica una exclusión del mundo, afirmar que se suspenden las cuestiones relativas al ser de la realidad son egregios malentendidos. Lo mismo vale para la afirmación de que Husserl es un solipsista metodológico. Dreyfus piensa que Husserl sólo opera con la noción de un ego aislado y sin cuerpo. 53 Pero, una vez más, estas opiniones pasan por alto el rol fundamental atribuido por Husserl al cuerpo en movimiento, ignoran la radicalidad de su fenomenología de la intencionalidad, no aprecian el constante esfuerzo por mostrar el impacto constitutivo de la alteridad. Hablando en términos generales, Dreyfus ofrece una errónea interpretación mentalista de la fenomenología husserliana. ${ }^{54}$ Sus críticas menosprecian todos

\footnotetext{
51 Sartre, J.P.: L'être et le neánt. Essais d'ontologie phénoménologique, Paris, Gallimard, 1943 p. $17-$ 18.

52 Cf. Dreyfus, H.L.: Being-in-the-World, Cambridge, MIT Press, 1991, p. 50.

53 Cf. Dreyfus, H.L. y Hall, H.: "Inroduction", en H.L. Dreyfus y H. Hall (eds.), Husserl, Intentionality, and Cognitive Sciences, Cambridge, MIT Prees, 1982, p. 119.

54 Cf. Zahavi , D.: "Husserl's Noema and the Internalism-Externalism Debate", Inquiry, 47 (1), 2004, p. 58.
} 
aquellos pasajes en los que Husserl niega explícitamente que el verdadero propósito de la epoché y la reducción sea dudar, olvidar, abandonar o excluir la realidad.

A nuestro juicio, la interpretación peca de una considerable insuficiencia textual incapaz de sostener la tesis de que Husserl es un solipsista metodológico. De una manera recurrente se cita siempre uno y el mismo parágrafo, a saber, el conocido parágrafo 49 de Ideas I. Éste es el parágrafo donde Husserl escribe que "la conciencia, considerada en su 'pureza', debe tenerse por un orden del ser encerrado en sí mismo, como un orden de ser absoluto en que nada puede entrar ni del que nada puede escapar". ${ }^{55}$ Ante una afirmación tan rotunda como ésta parece casi absurdo negar que Husserl defienda el solipsismo. Pero, como ocurre con frecuencia, la verdad del asunto es mucho más complicada. Incluso el citado parágrafo 49 está abierto a diferentes interpretaciones, como la clásica ofrecida por Tugendhat. Tugendhat afirma que sólo una lectura superficial de la reducción transcendental nos puede llevar a la conclusión de que el propósito husserliano sea aislar a la conciencia del mundo al que se dirige. Como señala Tugendhat, la reducción transcendental no nos retrotrae a un sujeto sin mundo; al contrario, nos coloca ante el fenómeno transcendental del mundo. Lo que se pone entre paréntesis en el parágrafo 49 es el mundo natural dado por supuesto, y es precisamente la operación de la reducción la que nos permite descubrir la correlación esencial entre mundo y subjetividad. 56

De esta manera, no sólo es posible leer Ideas I de una manera diferente a la de Heidegger (y, por extensión, a la de Dreyfus y Herrmann), sino que también es posible cuestionar su hipótesis de fondo, a saber, que Husserl permaneció fiel a un concepto cartesiano de la reducción transcendental según el cual la tarea de la fenomenología consiste en investigar la subjetividad pura de manera aislada y separada del mundo y de los otros. Pero, como sabemos, Husserl intentó superar lo que Kern (1962) calificó como la vía cartesiana de la reducción por medio de la llamada vía ontológica desarrollada, por ejemplo, en Crisis. La vía ontológica no parte de la autodonación inmediata del sujeto, sino que arranca del análisis de la donación de una región ontológica específica, digamos la región de los objetos ideales o de los objetos físicos. Sin embargo, a través de la actitud fenomenológica no sólo tomamos conciencia directa de la donación del objeto, sino que indirectamente también descubrimos la subjetividad como condición de posibilidad de manifestación como tal. Mientras que la vía cartesiana muestra a un sujeto separado e independiente de la realidad, proporcionando así munición a la extendida interpretación de que la fenomenología explora las estructuras de un sujeto autónomo, aislado y sin mundo, la vía ontológica deja claro que la investigación de la subjetividad es inseparable de

\footnotetext{
55 Husserl HUA III, p. 105 (cursiva y entrecomillado del autor).

56 Cf. Tugendhat. E.: Der Wahrheitsbegriff bei Husserl und Heidegger, Berlin, Walter de Gruyter, 1970, p. 263. Encontramos una interpretación similar en Crowell, S.G.: Husserl, Heidegger, and the Space of Meaning. Evanston: Northwestern University Press, 2001, pp. 170, 179, 200.
} 
una reflexión filosófica sobre el mundo. ${ }^{57}$ Desde este punto de vista, podemos decir que Husserl está interesado en la conciencia en cuanto campo de manifestación del mundo. 58

Ahora bien, esta conciencia no debe entenderse como una mente independiente del mundo, sino que implica una relación constitutiva con el campo de donación inmediata que es el mundo. En este sentido, la realidad depende de la subjetividad. Pero eso no niega o cuestiona la existencia del mundo real; simplemente se rechaza la interpretación objetivista de su estatuto ontológico. El mismo Husserl reconoce en La crisis de las ciencias europeas: "El hecho de que el mundo existe está fuera de toda duda. Pero otra cosa es comprender esta indubitabilidad y clarificar su legitimidad".59 Parafraseando una observación de Putnam: la mente no inventa el mundo, pero tampoco se limita a reflejarlo. 60

Nos hallamos, sin duda, ante uno de los problemas filosóficos que más preocupó a Husserl, a saber, el de cómo se constituye el mundo en la subjetividad. Muchas de las críticas dirigidas a Husserl insisten en que la constitución es un proceso creativo, con lo que se le acusa de un idealismo insostenible. Husserl nunca dio una respuesta clara a la cuestión de si la constitución debe ser comprendida como una creación o como una restauración de la realidad. En cualquier caso, afirmar que el sujeto es la condición de posibilidad para la aparición de los objetos no significa postular una conexión causal entre el primero y los segundos. La subjetividad constituyente no debería compararse con una especie de Big Bang: no inicia un proceso causal que determina los objetos. ¿Qué cabe entender exactamente por «constitución»? Por decirlo en breves palabras, constitución debe comprenderse como un proceso que permite la manifestación y significación. Como observa Heidegger, "constituir" no significa "producir" en el sentido de "fabricar", sino "dejar ver el ente en su objetividad". 61

57 Cf. Zahavi, D.: "Husserl's Noema and the Internalism-Externalism Debate”, Inquiry, 47 (1), 2004, p. 60 .

58 ¿Y cuál es la postura de Husserl tras el giro transcendental de Ideas I? Si uno toma las lecciones Filosofía primera y Fenomenología de la intersubjetividad o el conocido texto de la Crisis encontrará múltiples pasajes que afirman que la fenomenología transcendental incluye el mundo con todo su verdadero ser (HUA VIII, p. 424; HUA XV, p. 366; HUA VI, p. 154). Incluso en Ideas I, Husserl deja claro que la fenomenología eventualmente integra e incluye todo aquello que ha sido puesto entre paréntesis por razones metodológicas (HUA III, pp. 107, 159, 337). Así, afirmar, como hace Dreyfus, que el rasgo esencial de la fenomenología transcendental husserliana consiste en suspender o excluir toda cuestión relacionada con el ser de la realidad no es un hecho tan obvio. La afirmación de que Husserl es un solpsista metodológico es un hecho con escaso fundamento filosófico y textual.

${ }^{59}$ Husserl HUA VI, pp. 190-191.

60 Cf. Putnam, H.: Mind, Language, and Reality. Philosophical Papers II, Cambridge, Cambridge University Press, 1975, p. 1.

61 Heidegger GA 20, p. 97. 
En contra de otro malentendido ampliamente extendido, este proceso no tiene lugar como una cosa llovida del cielo, como si fuera deliberadamente iniciado y controlado ex nihilo por el ego transcendental. Husserl, al menos el Husserl tardío, piensa que la subjetividad es una condición de posibilidad necesaria de toda constitución, pero no es la única. La constitución es un proceso que implica diferentes instancias constituyentes entrelazadas, como la subjetividad, el mundo de la vida, el cuerpo y la intersubjetividad. ${ }^{62}$ En otras palabras, la subjetividad transcendental sólo puede constituir un mundo objetivo si está encarnada en un cuerpo, forma parte de un mundo social y comparte un mundo histórico-cultural. Como Husserl señaló en Ideas II: yo, nosotros y el mundo se pertenecen mutuamente. ${ }^{63}$ La subjetividad constituyente, por tanto, sólo alcanza una plena relación consigo misma en relación con los otros, es decir, en la intersubjetividad: ésta sólo existe y se desarrolla en la mutua interrelación entre sujetos que están referidos a un mismo mundo.

Lo que resulta particularmente relevante en este contexto es que el proceso de constitución presupone un elemento de facticidad, una predonación pasiva exenta de una participación o contribución activas del ego. ${ }^{64}$ Esto no debe llevarnos a pensar en una nueva forma de dualismo; más bien al contrario, la idea es que la subjetividad y el mundo no se pueden comprender separados el uno del otro. Dicho de otro modo, la constitución es un proceso que se despliega en la triple estructura subjetividad-mundo-intersubjetividad como el verdadero horizonte transcendental en el que pueden aparecer los objetos. De ahí que el Husserl de la fenomenología genética, como veremos a continuación, abandone la idea de una correlación estática entre el constituyente y lo constituido. La actividad constitutiva se caracteriza, más bien, por cierta reciprocidad en la medida en que el sujeto es constituido en el mismo proceso de constitución. Por tanto, afirmar que el sujeto transcendental permanece inalterado en su propia actividad constituyente es otro malentendido que hay que empezar a erradicar a la vista de la evidencia textual que nos proporcionan las investigaciones husserlianas de los años veinte en torno a la síntesis pasiva, a la intersubjetividad y al mundo de la vida.

\footnotetext{
62 Para un análisis del proceso de constitución espiritual, afectiva, corporal, intersubjetiva y vital véase Montero, F.: Retorno a la fenomenología, Barcelona, Anthropos, pp. 406-504.

${ }^{6} \mathrm{Cf}$. Husserl HUA IV, 128. Resulta bastante sorprendente comprobar qué pronto Husserl llegó a esta convicción. El propio Husserl señala que sus lecciones de 1910/11 Problemas básicos de la fenomenología (HUA XIII, pp. 77-194) son el lugar en el que se aborda la cuestión de la intersubjetividad y se resuelve el problema del solipsismo transcendental (HUA XVII 1974, p. 250; HUA XIII, p. 245; HUA XIV, p. 307). Ello demuestra que Husserl ya era consciente de la importancia de la intersubjetividad en la época de Ideas I (1913), a pesar de que en esa obra predomine una concepción egológica de la conciencia. Como luego escribió en el "Prólogo" de Ideas (1930), el segundo volumen de Ideas, que fue redactado en la misma época que el volumen primero, tenía que ofrecer una explicación suplementaria de la intersubjetividad.
}

$64 C f$. Husserl HUA XI, 328ss y HUA XIII, 427. 


\subsection{El papel de las sintesis pasivas}

En los análisis husserlianos sobre síntesis pasiva y activa encontramos una temprana descripción de la dimensión primordial de la experiencia y la entrada en escena de un nuevo método, a saber, el método genético. Esos análisis, recogidos en las Lecciones sobre Lógica Transcendental, forman un grupo de lecciones que Husserl impartió en la primera mitad de los años veinte, mismo período en el que se dedicó con intensidad al problema de la intersubjetividad (1921-1927) y de la reducción (1923/24). Como señala el traductor inglés, estas lecciones, ocupan un lugar histórico y conceptual central en su obra. ${ }^{65}$ Desde el punto de vista conceptual, estos análisis son representativos de la llamada fenomenología genética. Por una parte, superan el análisis estático peculiar de Ideas y, por otra, también anticipan las investigaciones generativas de la historia y el mundo de la vida. Encontramos aquí a un Husserl que empieza a distinguir en su fenomenología transcendental entre método estático y genético, respectivamente. 66

La fenomenología genética, por tanto, hace una distinción entre génesis activa, por un lado, y génesis pasiva, por otro. En la primera, el sujeto desempeña un papel productivo en la constitución de los objetos. Sus productos son herramientas, obras de arte, proposiciones matemáticas, teorías científicas, etcétera. Sin embargo, toda génesis activa presupone siempre una pasividad por la que uno se ve afectado de antemano. "Pasivo" no es equivalente a un estado de inactividad, sino que responde a un estar afectado involuntariamente por hábitos, patrones motores, disposiciones, motivaciones, emociones y recuerdos. En este sentido, el terreno fenomenológico de las síntesis pasivas es hoy día un campo de exploración especialmente interesante para la investigación psicológica y neurocientífica de las emociones y de los procesos cognitivos. 67

${ }^{6}$ Cf. Steinbock, A.J.: "Translator's Introduction”, en E. Husserl, Analyses Concerning Passive and Active Synthesis. Lectures on Transcendental Logic, Boston, Kluwer Publisher, 2001, p. xvi.

66 Para más información véase el interesante texto suplementario de 1921 "Statische und genetische Phänomenologie" ( $c f$. HUA XI, pp. 336-345). Estas lecciones sobre problemas fundamentales en la lógica transcendental han adquirido en esta última década una gran relevancia bajo la rúbrica de "síntesis pasiva”. Esto incluye, por extensión, un análisis del papel de la síntesis asociativa, la afección, la atención y los hábitos en la formación de sentido y constitución del objeto. Véase, por ejemplo, el enactive approach defendido por Thompson, quien reconoce abiertamente la importancia de la fenomenología genética de Husserl (Thompson, E.: Mind in Life. Biology, Phenomenology, and the Sciences of Mind, Cambridge, Harvard University Press, 2007, pp. 29-31). Por su parte, Roberto Walton ha dedicado gran parte de sus esfuerzos a aclarar las nociones husserlianas de generatividad y habitualidad (cf. Walton, R.: "Fenomenología y reflexión sobre el tiempo, la historia, la generatividad y la intersubjetividad", Lima, 2012, pp. 319-348).

67 A este respecto resulta especialmente relevante la llamada "neurofenomenología" ( $c f$. Thompson, E. et al.: "Neurophenomenology. An introduction for neurophilosophers", en A Brook y K. Akins (eds.), Cognition and the Brain. The Philosophy and Neuroscience Movement, New York, Cambridge, 2005, 
Mientras que en Experiencia y juicio se analizan los actos predicativos, la experiencia antepredicativa y la pasividad de la vida de la conciencia, en las lecciones sobre las síntesis activas se establece una clara diferencia entre pasividad y actividad. Como dice Husserl, "pasividad es en sí lo primero, porque toda actividad presupone esencialmente un subsuelo de pasividad y una objetualidad ya preconstituida". ${ }^{68}$ La aprehensión perceptiva y la identificación de sentido preconstituido de una pasividad originaria ya son formas de actividad, pero que se inscriben en un nivel precategorial. Es justo esta actividad en la pasividad la que media entre la pasividad originaria y la actividad propiamente categorial. La tendencia del yo a establecer objetivaciones activas sólo es posible a partir de la constitución originaria de las síntesis pasivas que emanan del constante acontecer de la corriente de la conciencia, sin la cual la conciencia no sería la que es. En contraste con la fenomenología estática de Ideas I, que sólo tiene en cuenta las objetividades ya acabadas en su constitución, Husserl desarrolla desde 1917 una fenomenología genética que contempla la situación temporal en la que se encuentra el sujeto. Este nuevo enfoque pone de relieve de qué forma surgen los sistemas de remisiones, con lo que se amplía considerablemente el campo de indagación fenomenológica. La experiencia pasada prefigura en cierta medida la manera de aguardar la experiencia futura, un hecho que se incrementa con la repetición de experiencias similares. Así, cada confirmación confiere más fuerza a la espera, mientras que cada fracaso la disminuye. El yo dispone ya siempre de un horizonte de conocimientos adquiridos, de familiaridad, así como de un sistema de tipificaciones, el cual se convierte en un componente permanente del sentido del objeto como resultado de una compleja síntesis de asociación en la que lo semejante evoca lo semejante. Este horizonte experimenta una constante modificación porque se amplía y corrige a la luz de nuevas experiencias.

De esta manera, Husserl pone al descubierto que el sujeto transcendental tiene una historia configurada por capacidades que quedan referidas en un análisis genético al acto de institución primordial. El yo no es sólo un polo idéntico de irradiación de actos, sino un sustrato de habitualidades que le convierten en portador de un estilo propio de ejecución de ellos. Este hecho, a su vez, diferencia al yo de los restantes yoes, lo que le permite a Husserl hablar de él como de una mónada. La relación con el mundo no depende, pues, exclusivamente de los actos conscientes y reflexivos, sino que está sujeta también a las afecciones y a las habitualidades del cuerpo. Con otras palabras, el yo es afectado no sólo en su pasividad primaria por los datos sensibles, sino también en una pasividad secundaria por sus actos sedimentados en adquisiciones permanentes que se conectan asociativamente con la vida actual.

pp. 40-97; Varela, F.J.: "Neurophenomenology: A Methodological Remedy for the Hard Problem", Journal of Consciousness Studies, 3, 1996, pp. 3330-350; Petitot, A. et al.: Naturalizing Phenomenology. Issues in Contemporary Phenomenology and Cognitive Science, Stanford, Stanford University Press, 1999.

68 Husserl HUA XXXI, p. 3. 
En cualquier caso, lo que resulta importante destacar es que la evolución interior de la fenomenología husserliana es algo más que una cuestión meramente interpretativa. Se trata, en realidad, de una cuestión filosófica. La fenomenología transcendental no se puede limitar a una filosofía de la conciencia egológica o de la subjetividad constituyente. En este sentido, el terreno fenomenológico de las síntesis pasivas es hoy día un campo de exploración especialmente interesante para la investigación psicológica y neurocientífica de las emociones y de los procesos cognitivos. En resumen, es útil ir más allá de las primeras interpretaciones de Husserl y reevaluar su obra entera sobre la base de una consideración rigurosa y a fondo. Esta reevaluación ya está en marcha y puede considerarse como parte de una apropiación más amplia de la fenomenología, que resulta de enorme interés no sólo para las ciencias cognitivas y la filosofía analítica de la mente, sino también para la filosofía misma. Quizá por ello resulte útil superar la división formal entre fenomenología reflexiva y fenomenología hermenéutica.

\section{Abreviaturas}

Textos Heidegger

$\begin{array}{ll}\text { GA 17 } & \text { Einführung in die phänomenologische Forschung } \\ \text { GA 19 } & \text { Platon, Sophistes } \\ \text { GA 20 } & \text { Prolegomena zur Geschichte des Zeitbegriffs } \\ \text { GA 21 } & \text { Logik. Die Frage nach der Wahrheit } \\ \text { GA 24 } & \text { Die Grundprobleme der Phänomenologie } \\ \text { GA 56/57 } & \text { Zur Bestimmung der Philosophie } \\ \text { GA 58 } & \text { Grundprobleme der Phänomenologie } \\ \text { GA 59 } & \text { Phänomenologie der Anschauund und des Ausdrucks } \\ \text { GA 61 } & \text { Phänomenologische Interpretationen zu Aristoteles } \\ \text { GA 63 } & \text { Ontologie. Hermeneutik der Faktizität } \\ \text { MWPh } & \text { Mein Weg in die Phänomenologie }\end{array}$

Textos de Husserl HUA I HUA III/1

Cartesianische Meditationen und Pariser Vorträge Ideen zu einer reinen Phänomenologie und phänomenologischen Philososphie. Erstes Buch

HUA IV

HUA VI

HUA VIII Ideen zu einer reinen Phänomenologie und phänomenologischen Philosophie. Zweites Buch Die Krisis der europäischen Wissenschaften und die transzendentale Phänomenologie. Eine Einleitung in die phänomenologische Philosophie. 


$\begin{array}{ll}\text { HUA XI } & \text { Analysen zur passiven Synthesis } \\ \text { HUA XIII } & \text { Zur Phänomenologie der Intersubjektivität. Erster Teil } \\ \text { HUA XIV } & \text { Zur Phänomenologie der Intersubjektivität. Zweiter Teil } \\ \text { HUA XV } & \text { Zur Phänomenologie der Intersubjektivität. Dritter Teil } \\ \text { HUA XVIII } & \text { Logische Untersuchungen. Erster Band } \\ \text { HUA XIX/1-2 } & \text { Logische Untersuchungen. Zweiter Band } \\ \text { HUA XXXI } & \text { Aktive Synthesen }\end{array}$

\section{Referencias bibliográficas}

Textos de Heidegger y Husserl

Heidegger, M.: "Mein Weg in die Phänomenologie“, en Zur Sache des Denkens, Tubinga, Max Niemeyer, 1976a, pp. 81-90.

HeIDEgGer, M.: Logik. Die Frage nach der Wahrheit (GA 21), Frankfurt am Main, Vittorio Klostermann, 1976b.

HeIDEGGer, M.: Phänomenologische Interpretationen zu Aristoteles. Einführung in die phänomenologische Forschung (GA 61), Frankfurt am Main, Vittorio Klostermann, 1986.

Heidegger, M.: Die Idee der Philosophie und das Problem der Weltanschaung. En Zur Bestimmung der Philosophie (GA 56/57), Frankfurt am Main, Vittorio Klostermann, 1987.

HeidegGer, M.: Ontologie. Hermeneutik der Faktizität (GA 63), Frankfurt am Main, Vittorio Klostermann, 1988a.

HeIDEgGer, M.: Prolegomena zur Geschichte des Zeitbegriffs (GA 20), Frankfurt am Main, Vittorio Klostermann, 1988b.

HeIDEgGer, M.: Die Grundprobleme der Phänomenologie (GA 24), Frankfurt am Main, Vittorio Klostermann, 1989.

HeIDEGGeR, M.: Grundprobleme der Phänomenologie (GA 58), Frankfurt am Main, Vittorio Klostermann, 1992a.

Heidegger, M.: Platon: Sophistes (GA 19), Frankfurt am Main, Vittorio Klostermann, 1992b.

HeIDegger, M.: Phänomenologie der Anschauung und des Ausdrucks (GA 59), Frankfurt am Main, Vittorio Klostermann, 1993.

HeIDEGGER, M.: Einführung in die phänomenologische Forschung (GA 17), Frankfurt am Main, Vittorio Klostermann, 1994.

Husserl, E.: Cartesianische Meditationen und Pariser Vorträge, Husserliana I. La Haya, Martinus Nijhoff, 1950.

HUSSERL, E.: Ideen zu einer reinen Phänomenologie und phänomenologischen Philosophie. Zweites Buch. Phänomenologische Untersuchungen zur Konstitution, Husserliana IV, La Haya, Martinus Nijhoff, 1952. 
HUSSERL, E.: Die Krisis der europäischen Wissenschaften und die transzendentale Phänomenologie. Eine Einleitung in die phänomenologische Philosophie, Husserliana VI, La Haya, Martinus Nijhoff, 1954.

Husserl, E.: Erste Philosophie (1923/24): Zweiter Teil. Theorie der phänomenologischen Reduktion. Husserliana VIII, La Haya, Martinus Nijhoff, 1959.

HusserL, E.: Zur Phänomenologie des inneren Zeitbewußtseins, Husserliana X, La Haya, Martinus Nijhoff, 1966a.

Husserl, E.: Analysen zur passiven Synthesis, Husserliana XI, La Haya, Martinus Nijhoff, 1966b

Husserl, E.: Zur Phänomenologie der Intersubjektivität. Texte aus dem Nachlass. Erster Teil: 1905-1920. Husserliana XIII, La Haya, Martinus Nijhoff, 1973a.

Husserl, E.: Zur Phänomenologie der Intersubjektivität. Texte aus dem Nachlass. Zweiter Teil: 1921-1928, Husserliana XIV, La Haya, Martinus Nijhoff, $1973 \mathrm{~b}$.

Husserl, E.: Zur Phänomenologie der Intersubjektivität. Texte aus dem Nachlass. Dritter Teil: 1929-1935, Husserliana XV, La Haya, Martinus Nijhoff, 1973c.

Husserl, E.: Logische Untersuchungen. Erster Band. Prolegomena zur reinen Logik, Husserliana XVIII, La Haya, Martinus Nijhoff, 1975.

HUSSERL, E.: Ideen zu einer reinen Phänomenologie und phänomenologischen Philosophie. Erstes Buch, Husserliana III/1, La Haya Martinus Nijhoff, 1976.

HusserL, E.: Logische Untersuchungen. Zweiter Band, Husserliana XIX/1-2, La Haya, Martinus Nijhoff, 1984.

Husserl, E.: Aktive Synthesen: Aus der Vorlesung ,Transzendentale Logik (1920/21). Ergänzungsband zu ,Analysen zur passiven Synthesis ', Husserliana XXXI, Dordrecht, Kluwer Academic Publishers, 2000.

Literatura secundaria

ADRIÁN, J.: "Hermeneutische versus reflexive Phänomenologie. Eine kritische Revision Heideggers früher Stellung zu Heidegger ausgehend vom Kriesgnotsemester 1919”, Analecta Husserliana LXXXVIII, 2005, pp. 157173.

ADRIÁN, J.: Heidegger y la genealogía de la pregunta por el ser. Una introducción temática y sistemática de su obra temprana, Barcelona, Herder, 2010.

ADRIÁN, J.: "El joven Heidegger y los prepuestos metodológicos de la fenomenología hermenéutica", Thémata. Revista de Filosofia, 44, 2011, pp. 212-238.

Crowell, S.G.: Husserl, Heidegger, and the Space of Meaning. Evanston: Northwestern University Press, 2001.

Damasio, A.: Self Comes to Mind. Constructing the Conscious Brain, New York, Pamtheon Books, 2010.

DreYFus, H.L.: "Husserl's Epiphenomenology", en H.R. Otto y J.A. Tuedio (eds.), Perspectives on Min, Dordrecht, Reidel, 1988, pp. 84-104.

DREYFus, H.L.: Being-in-the-World, Cambridge, MIT Press, 1991. 
Dreyfus, H.L. y Hall, H.: "Inroduction", en H.L. Dreyfus y H. Hall (eds.), Husserl, Intentionality, and Cognitive Sciences, Cambridge, MIT Prees, 1982, pp. 1-27.

Dennett, D.C.: Consciousness Explained, Boston, Little Brown, 1991.

FABRIS, A.: "L'ermeneutica della fatticità nei corsi friburghesi dal 1919 al 1923", en F. Volpi (ed.), Heidegger, Roma, Laterza, 1997, pp. 57-106.

GADAMER. H.-G.: Wahrheit und Methode. Grundzüge einer philosophischen Hermeneutik (Gesammelte Werke, Band 1), Tübingen, J.C.B. Mohr, 1986.

Grondin, J.: Einführung in die philosophische Hermeneutik, Darmstadt, Wissenschaftliche Buchgesellschaft, 1991.

Habermas, J.: Der philosophische Diskurs der Moderne, Frankfurt am Main, Suhrkamp, 1985.

Herrmann, F.-W.v.: Der Begriff der Phänomenologie bei Husserl und Heidegger, Frankfurt am Main, Vittorio Klostermann, 1981.

Herrmann, F.-W.v.: Wege und Methode. Zur hermeneutischen Phänomenologie des seinsgeschichtlichen Denkens, Frankfurt am Main, Vittorio Klostermann, 1990.

Herrmann, F.-W.v.: Hermeneutik und Reflexion. Der Begriff der Phänomenologie bei Heidegger und Husserl, Frankfurt am Main, Vittorio Klostermann, 2000.

Kalariparambil, T.: Das befindliche Verstehen und die Seinsfrage, Berlin, Duncker\&Humblot, 1999.

KrIEGEL, U.: "Consciousness and Self-consciousness", The Monist, 87 (2), 2004, pp. 182-205.

LARA, F.: Phänomenologie der Möglichkeit. Grundzüge der Philosophie Heideggers 1919-1923, Friburgo y Munich, Karl Alber, 2008.

LAZZARI, R. (2002): Ontologia de la fatticità. Prospettive sul giovanne Heidegger. Milano: Franco Angeli.

LiangKang, N.: "Urbewusstsein und Reflexion bei Heidegger", Husserl Studies, 15, 1998, pp. 77-99.

McIntyre, R.: "Husserl and Representational Theory of Mind", Topoi, 5, 1986, pp. 101-113.

MERKER, B.: Selbsttäuschung und Selbsterkenntnis. Zu Heideggers Transformation der Phänomenologie Husserls, Frankfurt am Main, Suhrkamp, 1988.

Metzinger, T.: Being No One, Cambridge, MIT Press, 2003.

Montero, F.: Retorno a la fenomenología, Barcelona, Anthropos.

NATORP, P.: Allgemeine Psychologie,Tübingen, J.C.B. Mohr, 1912.

NAtorp, P.: "Husserls Ideen einer reinen Phänomenologie", Logos, 7, 1917/18, pp. 215-240.

Peтітот, A. et al.: Naturalizing Phenomenology. Issues in Contemporary Phenomenology and Cognitive Science, Stanford, Stanford University Press, 1999.

PögGeler, O.: Schriften zu einer hermeneutischen Philosophie, Freiburg y Munich, Karl Alber, 1994. 
Putnam, H.: Mind, Language, and Reality. Philosophical Papers II, Cambridge, Cambridge University Press, 1975.

RINOFNER-KREIDL, S.: "Rezension von F.-W. von Herrmanns ,Hermeneutik und Reflexion“", Journal Phänomenologie, 16, 2001, pp. 90-94.

RoDRíguEz, R.: La transformación hermenéutica de la fenomenología. Una interpretación de la obra temprana de Heidegger, Madrid, Tecnos, 1997.

SARTRE, J.P.: La transcendance de l'ego, Paris, Vrin, 1936.

SARTre, J.P.: L'être et le neánt. Essais d'ontologie phénoménologique, Paris, Gallimard, 1943.

SARTre, J.P.: "Conscience de soi et connaisance de soi", Bulletin de la Société Française de Philosophie, 42, 1948, pp. 49-91.

SteInBock, A.J.: "Translator's Introduction", en E. Husserl, Analyses Concerning Passive and Active Synthesis. Lectures on Transcendental Logic, Boston, Kluwer Publisher, 2001, pp. i-iv.

Thompson, E. et al.: "Neurophenomenology. An introduction for neurophilosophers", en A Brook y K. Akins (eds.), Cognition and the Brain. The Philosophy and Neuroscience Movement, New York:, Cambridge, 2005, pp. 40-97.

Thompson, E.: Mind in Life. Biology, Phenomenology, and the Sciences of Mind, Cambridge, Harvard University Press, 2007.

Tugendhat. E.: Der Wahrheitsbegriff bei Husserl und Heidegger, Berlin, Walter de Gruyter, 1970.

VARELA, F.J.: "Neurophenomenology: A Methodological Remedy for the Hard Problem", Journal of Consciousness Studies, 3, 1996, pp. 3330-350.

WALton, R.: "Fenomenología y reflexión sobre el tiempo, la historia, la generatividad y la intersubjetividad", Lima, 2012, pp. 319-348.

Xolocotzi, A.: Der Umgang als Zugang. Der hermeneutisch-phänomenologische Zugang zum faktischen Leben in den frühen Freiburger Vorlesungen, Berlin, Duncker\&Humblot, 2002.

Zahavi, D.: Husserl and Transcendental Intersubjectivity. A Response to the Linguistic-Pragmatic Critique, Athens, Ohio University Press, 2001.

ZAHAVI, D.: "How to investigate subjectivity: Natorp and Heidegger on reflection", Continental Philosophy, 36, 2003a, pp. 155-176.

Zahavi, D.: Husserl's Phenomenology, Stanford, Stanford University Press, 2003b ZAHAVI, D.: "Husserl's Noema and the Internalism-Externalism Debate", Inquiry, 47 (1), 2004, pp. $42-66$.

Jesús Adrián Escudero

Departamento de Filosofía

Universidad Autónoma de Barcelona

jesus.adrian@uab.es 